\title{
La discapacidad bajo la lupa de los derechos humanos
}

Florencia Buscarolo'

\section{Universidad Nacional de San Luis}

\section{Aporte de Estudiante}

Resumen: ¿Qué sucede con la discapacidad en el ámbito internacional? Esta es la pregunta que se pretende responder en este ensayo. Sin embargo, la respuesta no es solamente desde una mirada jurídica, sino que, por el contrario, se plantea una mirada filosófica y sociológica de la discapacidad. Este análisis reflexivo se establece a partir del "fenómeno de los derechos humanos" planteado por Eduardo Rabossi (1989). Desde este nuevo paradigma, que engloba a los derechos humanos (DD. HH) en general, se describe la situación de las personas con capacidades diferentes en relación a la normativa internacional actual sobre la temática, su operatividad en diferentes ámbitos, la trama ideológica en la que se desarrolla y su efectiva vigencia, que ha ido dando lugar a los diferentes modelos que se describen en este texto. El período temporal tenido en cuenta para realizar tales descripciones es a partir del 10 de diciembre de 1948 hasta la actualidad. Ello debido a que en esa fecha fue sancionada la Declaración Universal de los Derechos Humanos que forma parte de la denominada Carta de Naciones Unidas. La sanción de ese y otros instrumentos, sumado a la creciente existencia de organismos internacionales, produjo lo que Rabossi llama el fenómeno de los derechos humanos (fdh).

\section{Introducción}

Eduardo Rabossi (1989) en su texto sobre El fenómeno de los derechos humanos y la posibilidad de un nuevo paradigma teórico, describe la existencia de una nueva línea de pensamiento. Este autor considera que hay hechos históricos que han creado el ambiente favorable para hablar ya de un "fenómeno" y no solo de un conjunto de normas. Tales hechos se relacionan con la progresiva sanción de instrumentos internacionales sobre DD. HH y la creciente existencia de organismos universales, ya sean formales o no formales. Estos acontecimientos produjeron lo que Rabossi llama el fenómeno de los derechos humanos, que es definido como "la existencia en nuestro mundo actual de un fenómeno específico, históricamente dado, sumamente complejo, extraordinariamente dinámico, de alcances universales y de consecuencias revolucionarias" (Rabossi, 1989, p. 328).

\footnotetext{
1 Estudiante avanzada de la carrera de Abogacía de la Universidad Nacional de San Luis. Correo electrónico: florbuscarolo1@gmail.com
} 
Richard Rorty (1995) apoya la idea de Rabossi de considerar a los derechos humanos como un hecho cultural separado de los fundamentos fundacionalistas. Rorty entiende que debemos dejar de lado a pensadores como Platón y Kant, debido a que pretenden encontrar la naturaleza del ser humano en argumentos ahistóricos. Estos filósofos se basan en concepciones racionalistas para diferenciar a los seres humanos de los animales; consideran que los seres humanos estamos dentro de una categoría superior ya que, mientras que los animales solamente sienten, los "hombres" también piensan. Rorty, por el contrario, concibe que para entender el fenómeno de los derechos humanos debemos ser irracionales, lo que implica negar "la existencia de hechos moralmente pertinentes que tengan una existencia transcultural" (p. 6).

\section{La discapacidad interpretada desde el fenómeno de los derechos humanos}

El análisis de la discapacidad se desarrollará en cuatro puntos: a) la normativa internacional aplicable, b) los aspectos operativos del fdh, c) la trama ideológica y d) la relación entre el ideal de los DD. HH y su efectiva vigencia.

a) Debido a que aquí no se pretende formular un estudio detallado de la normativa aplicable a la discapacidad, solo se nombrarán algunos tratados internacionales, a saber: la Convención Americana de Derechos Humanos (CADH), el Protocolo Adicional a la CADH en materia de Derechos Económicos, Sociales y Culturales, la Convención Interamericana para la Eliminación de todas las formas de Discriminación contra las Personas con Discapacidad, la Convención sobre las Personas con Discapacidad, entre otros.

b) Esos plexos normativos impactan en el ámbito nacional ya que, ante la violación de los mismos, los ciudadanos tienen la posibilidad de acudir a los organismos internacionales. Siempre que el Estado demandado sea parte de la Organización de Naciones Unidas (ONU), o de la Organización de Estados Americanos (OEA) en nuestro caso.

Bajo este razonamiento, podemos preguntarnos qué sucede si algún Estado no ha ingresado a los organismos internacionales, o qué pasa si un Estado no ratificó el tratado necesario para reclamar los derechos reconocidos. En esos casos, ¿las personas serían titulares de derechos humanos? ¿Podrían reclamar los daños ocasionados? ¿Tendrían acceso a la justicia internacional? ¿Qué pasaría si un Estado democrático deja de serlo? Los ciudadanos de ese Estado ¿Se beneficiarían con las posibilidades de obtener la protección brindada por esos organismos?

De este modo, podemos indagar sobre la validez del nuevo orden jurídico internacional, puesto que son los Estados los que delegaron parte de su soberanía en otras instituciones para que éstas puedan controlarlos. Sin embargo, siguen siendo los mismos 
Estados los que pueden negarse a este control, desaprobando los medios internacionales de intervención.

c) En relación a la trama ideológica, se seguirá a la autora Agustina Palacios (2008) y a su texto sobre El modelo social de discapacidad: orígenes, caracterización y plasmación en la Convención Internacional sobre los Derechos de las Personas con Discapacidad.

Existen tres modelos que aportan distintas miradas sobre la discapacidad. El primero de ellos es el de la prescindencia, el que propugna que el origen de la discapacidad se debe a causas religiosas. Considera que las personas con capacidades diferentes son innecesarias para la sociedad y que, por ende, se puede prescindir de ellas.

El segundo es el modelo rehabilitador, que considera como causa de la discapacidad a la ciencia. Propone la rehabilitación de las personas con discapacidad, aunque ello implique desaparecer o esconder la deficiencia que esa persona posee. Para ello, son resguardados en instituciones que buscan soluciones médicas a los problemas de los pacientes.

Finalmente, el tercer modelo que plantea la autora es el social, el cual concibe que la discapacidad surge cuando la sociedad no logra adoptar las medidas necesarias para incorporar a todos los individuos a la vida en la comunidad. Considera a la autonomía de la voluntad como principal elemento para que todas las personas puedan decidir el rumbo de sus vidas, eliminando la mayor cantidad de barreras posibles.

A los modelos antes enunciados, se agrega uno nuevo denominado de la diversidad. Este nuevo modelo deja de tener como eje central a la capacidad, para concentrarse en la diversidad. Esta última es vista como una realidad irrefutable, que le otorga a cada sociedad una riqueza específica proveniente de la multiplicidad de personas con características únicas. Esta nueva perspectiva tiene como eje teórico a la dignidad de las personas, “... una dignidad que es inherente a todos los seres humanos y que no está vinculada a la capacidad" (Palacios y Romañach, 2008, p. 41).

d) Con respecto al último punto de este análisis, cabe mencionar que el ideal de los DD. HH surge con la modernidad. Es decir, los derechos humanos aparecen en el mundo moderno de la "burguesía, del dominio de la naturaleza, de la esperanza en el progreso y en la felicidad de una sociedad hecha a escala humana, del presente histórico, de la dominación y la circulación del capital" (Raffin, 2006, p. 1). Los DD. HH fueron una conquista de la clase burguesa, de esos hombres, mayores, blancos y propietarios. "De ahí que al principio, todas las otras formas humanas (formas no burguesas y no europeas), que no entran dentro de los estrechos límites del sujeto moderno así definido, hayan sido olvidadas, ignoradas y silenciadas como "exclusiones" de su definición" (Raffin, 2006, p. 2). 
Los ideales que existían al comienzo de la emergencia de los DD. HH no son los mismos que posee la sociedad actualmente. En estos tiempos, los derechos fundamentales buscan proteger a los grupos más vulnerables de la comunidad, como lo son los niños, los ancianos, las mujeres, las personas con discapacidad, entre otros. Ya no se pretende excluir a nadie, sino que, por el contrario, mientras más personas ingresen dentro del radio de protección de los DD. HH es mejor para la comunidad internacional. Sin embargo, en la efectiva vigencia de los derechos humanos, los ideales se debilitan un poco. El mundo occidental se encuentra sumergido en un modelo económico capitalista, que induce a los sujetos a actuar de manera individual y guiados por sus propios intereses. La economía y el derecho son dos disciplinas que se relacionan íntimamente produciendo un conflicto entre lo que se debe hacer y lo que conviene económicamente hacer. Como consecuencia tenemos derechos más rentables que otros, ya que es más barato para el Estado garantizar elecciones limpias y competitivas que la cobertura médica a personas con capacidades diferentes.

\section{Conclusiones}

Con esta nueva línea de pensamiento creada por el fenómeno de los derechos humanos podemos establecer otra mirada sobre los derechos fundamentales de las personas con capacidades diferentes. Las nomas son claras respecto de lo que les corresponde a las personas con diversidad funcional, sin embargo, son numerosos los casos en los que las normas jurídicas parecen no estar escritas. Encontramos Estados que no han adherido a los organismos internacionales, como así también países que estando dentro de dichos organismos, no han ratificado los tratados de derechos humanos de las personas con discapacidad. Asimismo, los instrumentos internacionales deben optar por uno de los modelos explicados en este ensayo, y aplicarlo. Un ejemplo de ello es la Convención Sobre las Personas con Discapacidad que adopta el modelo social y ello se ve reflejado en su contenido.

\section{Referencias bibliográficas}

Palacios, A. (2008). El modelo social de discapacidad: orígenes, caracterización y plasmación en la Convención Internacional sobre los Derechos de las Personas con Discapacidad. Madrid: Grupo editorial CINCA.

Palacios, A., Romañach, J. (2008). El modelo de la diversidad: una nueva visión de la bioética desde la perspectiva de las personas con diversidad funcional (discapacidad). Revista sociológica de pensamiento crítico, (2) 2, 37-47. 
Rabossi, E. (1989). El fenómeno de los derechos humanos y la posibilidad de un nuevo paradigma. Revista del centro de Estudios Constitucionales, 3, 323-343.

Raffin, M. (2006). La experiencia del horror. Buenos Aires: Editores del Puerto S.R.L.

Rorty, R. (1995). Derechos humanos racionalidad y sentimentalismo. Praxis Filosófica Ética y Política. Universidad del Valle (Cali). Traducción de Anthony Sampson.

\section{Documentos consultados}

Organización de Estados Americanos. (1969). Convención Americana de los Derechos Humanos.

Organización de Estados Americanos (1988). Protocolo Adicional a la Convención Americana de los Derechos Humanos.

Organización de Estados Americanos (1999). Convención Interamericana para la Eliminación de todas las Formas de Discriminación contra las Personas con Discapacidad.

Organización de Naciones Unidas. (2006). Convención sobre las Personas con Discapacidad. 